\title{
Selected aspects of nutrition in palliative care
}

\begin{abstract}
Proper nutrition in palliative care is essential to achieve a good quality of life of patients and better treatment results. The diet should include the proper amount of calories and nutrients such as proteins, omega 3 fatty acids, dietary fibre, vitamin D and vitamin C. The meals must be balanced, tasty, diverse and appetizing. In this paper, an example of one-day diet for adult palliative care patients is proposed.
\end{abstract}

Palliat Med Pract 2019; 13, 1: 17-21

Key words: anorexia, cachexia, diet, nutrition, palliative care, quality of life

\section{Introduction}

The main aim of palliative care is to improve the quality of life of patients with life-threatening diseases [1]. Without doubts, proper nutrition is essential to achieve the goals of palliative care. The nutritional needs of palliative care patients differ from the healthy population in the following aspects: increased metabolism (hypermetabolism), impaired organ function, increased nutrient losses and malnutrition [2]. Moreover, loss of appetite (anorexia), difficulties in swallowing, taste alterations are observed in palliative care patients [3]. All mentioned alterations result from cancer or its treatment, e.g. surgery, chemotherapy or radiotherapy.

\section{Nutrition in palliative care \\ Increased calories intake}

Cancer cachexia is strictly related to involuntary weight loss. It may be the cause of decreasing the quality of life, responsiveness to chemotherapy and increased morbidity [4]. Additionally, patients with cancer have usually reduced calories intake [5]. There- fore, to optimize nutrition, in most of palliative care patients diet should include more calories than common diet. Therefore, it is beneficial to add to the diet some products rich in calories in a small volume. The best high-calorie foods among dairy products are butter $(735 \mathrm{kcal} / 100 \mathrm{~g})$, sour cream $18 \%$ fat (184 kcal/100 g), whipped cream (231 kcal/100 g), whole eggs (139 kcal/100 g), cheese $(380 \mathrm{kcal} / 100 \mathrm{~g})$, full fat yogurts $(117 \mathrm{kcal} / 100 \mathrm{~g})$ and milk powder $(478 \mathrm{kcal} / 100 \mathrm{~g})$. Sweets like chocolate (approximately $540 \mathrm{kcal} / 100 \mathrm{~g})$ and honey (324 kcal/100 g) as well as nuts (approximately $640 \mathrm{kcal} / 100 \mathrm{~g}$ ), seeds (about $560 \mathrm{kcal} / 100 \mathrm{~g})$ and peanut butter $(695 \mathrm{kcal} / 100 \mathrm{~g})$ are also desired in malnutrition. Some additional products such as mayonnaise (714 kcal/100 g), dips, sauces may increase the calories intake. Moreover, same fruits, vegetables and products made from them can be good sources of calories. To this products belong avocado $(160 \mathrm{kcal} / 100 \mathrm{~g})$, banana $(95 \mathrm{kcal} / 100 \mathrm{~g})$, dried fruits (raisins, dates, figs) (approximately $280 \mathrm{kcal} / 100 \mathrm{~g}$ ), coconut flesh (283 kcal/100 g). They also include fiber, antioxidants and nutrients, therefore they are particularly beneficial. Fats, both from plants as avocado

\footnotetext{
Address for correspondence:

Karolina Kuźbicka

Department of Pharmacology, Medical University of Gdańsk

ul. Dębowa 23

80-204 Gdańsk, Poland

e-mail: k.kuzbicka@gmail.com
}

Palliative Medicine in Practice 2019; 13, 1, 17-21

Copyright (C) Via Medica, ISSN 2545-0425

DOI: 10.5603/PMPI.2019.0003 
oil, coconut oil (approximately $880 \mathrm{kcal} / 100 \mathrm{~g}$ ) and included in fishes or red meat deliver a lot of energy in a small volume.

\section{Proteins}

Cancer patients often suffer from protein-calorie malnutrition, which can lead to the loss of skeletal muscle and deterioration in the quality of life [6]. Proteins are important to develop and repair body tissues and are involved in the production of some hormones and enzymes. In palliative patients the demand for proteins can be approximately $1.5-2 \mathrm{~g}$ per kilogram of body mass and two third of them should be complete proteins [7]. In comparison, the average normal diet should include $0.8 \mathrm{~g}$ per kilogram, i.e. about $50 \mathrm{~g}$ per day. The complete proteins in comparison to incomplete proteins contain all eight essential amino acids which cannot be produced in the human body. Products which are especially rich in complete proteins are: meat, fish, eggs and dairy products. Plant based sources of complete proteins are: soybeans, hempseeds, and quinoa. It is worth to increase the amount of protein in the standard dishes of palliative care patient's diet by the addition of milk powder to scrambled eggs, sauces, minced meat and milk desserts. It is also possible to combine incomplete proteins to obtain a full spectrum of essential amino acids. Such combinations include: whole grains products with nuts or seeds, whole grains products with beans. Also some specialized medical nutritional products are available, which are rich in calories and proteins. The bottle of $125 \mathrm{ml}$ of such product contains approximately $300 \mathrm{kcal}$ and $15-18 \mathrm{~g}$ of proteins. Moreover, it has been demonstrated that supplementation of essential amino acids, especially leucine, probably stimulates protein synthesis in human skeletal muscles, which can be very beneficial in palliative care patients suffering from cachexia [8].

\section{Omega 3 fatty acids}

Other important nutrients are omega 3 fatty acids, which are unsaturated fatty acids with the first double bond between the third and fourth carbon atoms from the terminal methyl end. Three types of omega 3 fatty acids extremely important to human nutrition are: $\alpha$-linolenic acid (ALA), eicosapentaenoic acid (EPA) and docosahexaenoic acid (DHA). Omega 3 fatty acids are proved to be beneficial in many health problems including hypertension [9] and depression [10]. Moreover, they can play a role in the reduction of inflammation respond. Chronic inflammation significantly contributes to the development of cachexia in cancer patients [7]. Therefore omega 3 fatty acids in palliative care patients' diet may prevent cachexia. It is very important to derive these fatty acids with nutrition because of very limited ability to convert ALA to EPA and DHA [11]. Moreover, this conversion is competitive with omega 6 fatty acids, which appear more profusely in the modern human diet [12]. Products which contain ALA include walnut, seeds, algal oil, flaxseed oil, and hemp oil. EPA and DHA can be found in fish (especially salmon, mackerel, sardine, trout), rapeseed oil, soybean oil. Colomer et al. have demonstrated in a meta-analysis that supplementation of about $2 \mathrm{~g}$ of EPA and $1 \mathrm{~g}$ of DHA can improve appetite and prevent weight loss in advanced cancer patients. The duration of supplementation differs between the researchers, but it seems that good results can be obtained after 8-week supplementation [13]. Taking into consideration that the incidence of side effects of such supplementation is very low, it is worth considering it in palliative care patients.

\section{Dietary fibre}

It is also worth to emphasize the role of dietary fibre in the diet which can help to provide the proper gut passage and therefore manage with constipation, although its role in the management of constipation in palliative care patients is limited. Constipation is the side effect of repeated administration of opioids, for example, morphine, and concerns a lot of patients. Products which are rich in dietary fibre are vegetables, fruits, whole grains products. Avocado is a fruit that is particularly beneficial in the palliative care patient diet. It is rich in dietary fiber $(6.8 \mathrm{~g}$ per $100 \mathrm{~g}$ ) [14]. Moreover, it contains a great number of calories in comparison to other fruits, which can help to avoid weight loss. A standard portion of avocado is one half of the fruit (about $70 \mathrm{~g}$ ) every day.

\section{Vitamin D}

The proper intake of vitamins is also vital in palliative care patients' diet. Vitamin $D$ is not only crucial for proper formation and mineral homeostasis of bones [15], but it is also vital for the proper immune and nervous systems function $[16,17]$. It was demonstrated that cancer patients more often suffer from vitamin $D$ deficiency (<50 nmol/L) [18]. Moreover, cancer patients with a lower vitamin $D$ level experienced more intense pain and in consequence, needed higher opioids doses [19]. Supplementation of vitamin $D$ in cancer patients improves pain management and reduces susceptibility to infections [20], which results in fewer opioids and antibiotics usage and a smaller 
number of their side effects. There is evidence that vitamin $\mathrm{D}$ can be also beneficial in depressive disorders [21], which may be helpful in palliative care as symptoms of depression are very common in cancer patients. The main source of vitamin $D$ in the body is the endogenous synthesis in the skin, which requires the presence of sunlight. A small amount of vitamin $D$ is delivered through diet. Products which contain vitamin $D$ are fish, meat, and plants [22]. Oral supplementation of this vitamin is very popular and advisable as it is well-tolerated and safe. The recommended dose of vitamin $D$ supplementations for cancer patients is $4000 \mathrm{IU} /$ day [20].

\section{Vitamin C}

Another vitamin that seems to be vital in palliative care patients diet is vitamin C (ascorbate). Vitamin C plays a crucial role in the human body. It is the antioxidant and the cofactor of several important enzymes $[23,24]$. Humans cannot synthesize vitamin $C$, so it is crucial to delivering it through the diet. Palliative care patients very often face with vitamin $C$ deficiency (plasma vitamin C concentrations $<11 \mu \mathrm{mol} / \mathrm{L}$ ) [25] especially because it has been demonstrated that patients under oxidative stress, for example in surgical intensive care, have greater requirements for vitamin $C$ [26]. The administration of anti-cancer drugs may induce a decrease in patients' vitamin $\mathrm{C}$ concentrations [27-29]. Although the effect of vitamin C on cancer treatment is controversial, it has been demonstrated that high doses of this vitamin can reduce pain, which is the biggest issue to deal with in palliative care patients. In a retrospective study of 39 advanced cancer patients, Günes-Bayir and Kiziltan have demonstrated that there was a median reduction of $50 \%$ in pain among the patients who obtained an infusion of $2.5 \mathrm{~g}$ ascorbic acid [30]. Moreover, in the prospective study of 39 advanced cancer patients administration of vitamin C ( $10 \mathrm{~g}$ vitamin C intravenously twice with a 3-day interval and an oral intake of $4 \mathrm{~g}$ vitamin $\mathrm{C}$ daily for a week) improved the quality of life reported as better physical, emotional and cognitive functioning as well as less intensity of symptoms such as fatigue, nausea, vomiting, pain, and appetite loss [31]. In the retrospective multicenter cohort study of 125 women diagnosed with breast cancer patients were divided into two groups: the group of 53 patients who were treated with $7.5 \mathrm{~g}$ of vitamin C for 4 weeks in addition to standard anti-cancer therapy and control group of 72 women who obtained only standard anti-cancer therapy. The first group reported less chemotherapy and radiotherapy side effects (nausea, loss of appetite, depression, sleep disorders) [32]. Moreover, there are studies reporting a substantial decrease in opioid requirements in advanced cancer patients $[33,34]$.

\section{One day-diet}

Please find below an example of a balanced one day-diet for palliative care patients. It contains $2900 \mathrm{kcal}, 120 \mathrm{~g}$ of proteins, $99 \mathrm{~g}$ of fat, $370 \mathrm{~g}$ of carbohydrates and $45 \mathrm{~g}$ of fibre.

\section{First breakfast}

Scrambled eggs, sandwiches, fruit juice:

- 2 eggs (120 g)

- 2 slices of whole grain bread $(80 \mathrm{~g})$

- 2 spoons of butter $(10 \mathrm{~g})$

- 2 slices of ham poultry $(30 \mathrm{~g})$

- glass of fresh fruit juice $(250 \mathrm{~mL})$

\section{Second breakfast}

Milk cocktail:

- a glass of natural yoghurt (150 g)

- 1 standard banana (130 g)

- strawberries/raspberries (150 g)

- small spoon of honey (12 g)

- a spoon of milk powder (15 g)

- $1 / 2$ of a small onion $(60 \mathrm{~g})$

- $1 / 2$ glass of tomato puree $(50 \mathrm{~g})$

- 2-3 spoons of cream (40 g)

\section{Lunch}

Meat balls in tomato sauce, avocado salad:

- minced poultry meat $-150 \mathrm{~g}$

- $1 / 3$ of egg

- one spoon of semolina (10 g)

- $1 / 2$ glass of barley ( $80 \mathrm{~g}$ of dry product)

- $1 / 2$ of a medium avocado

- 1 medium tomato

Snack

Yeast dough and fruit:

- yeast dough $-120 \mathrm{~g}$

- 1 standard orange (200 g)

\section{Supper}

Sandwiches, cottage cheese with vegetables and seeds:

- 2 slices of whole grain bread $(80 \mathrm{~g})$

- 2 spoons of butter $(10 \mathrm{~g})$

- 2 slices of ham poultry $(30 \mathrm{~g})$

- $1 / 2$ glass of cottage cheese $(80 \mathrm{~g})$

- a few radishes $(50 \mathrm{~g})$

- a few slices of cucumber $(50 \mathrm{~g})$

- 2 spoons of pumpkin seeds $(15 \mathrm{~g})$. 


\section{Summary}

To sum up, in palliative care patients it is important to emphasize the right amount of calories and macronutrients as it can improve the patient's nutritional status and the quality of life.

\section{References}

1. http://www.who.int/cancer/palliative/definition/en/. (5.12.2018).

2. van Bokhorst-de van der Schueren MAE. Nutritional support strategies for malnourished cancer patients. Eur J Oncol Nurs. 2005; 9 Suppl 2: S74-S83, doi: 10.1016/j. ejon.2005.09.004, indexed in Pubmed: 16437760.

3. Ravasco P. Aspects of taste and compliance in patients with cancer. Eur J Oncol Nurs. 2005; 9 Suppl 2: S84-S91, doi: 10.1016/j.ejon.2005.09.003, indexed in Pubmed: 16437761.

4. Sadeghi M, Keshavarz-Fathi M, Baracos V, et al. Cancer cachexia: Diagnosis, assessment, and treatment. Crit Rev Oncol Hematol. 2018; 127: 91-104, doi: 10.1016/j. critrevonc.2018.05.006, indexed in Pubmed: 29891116.

5. Bovio G, Bettaglio R, Bonetti G, et al. Evaluation of nutritional status and dietary intake in patients with advanced cancer on palliative care. Minerva Gastroenterol Dietol. 2008; 54(3): 243-250, indexed in Pubmed: 18614973.

6. Gangadharan A, Choi SE, Hassan A, et al. Protein calorie malnutrition, nutritional intervention and personalized cancer care. Oncotarget. 2017; 8(14): 24009-24030, doi: 10.18632/oncotarget.15103, indexed in Pubmed: 28177923.

7. Seruga $B$, Zhang $H$, Bernstein $\sqcup$, et al. Cytokines and their relationship to the symptoms and outcome of cancer. Nat Rev Cancer. 2008; 8(11): 887-899, doi: 10.1038/nrc2507, indexed in Pubmed: 18846100.

8. Drummond MJ, Rasmussen BB. Leucine-enriched nutrients and the regulation of mammalian target of rapamycin signalling and human skeletal muscle protein synthesis. Curr Opin Clin Nutr Metab Care. 2008; 11(3): 222-226, doi: 10.1097/MCO.0b013e3282fa17fb, indexed in Pubmed: 18403916.

9. Miller PE, Van Elswyk M, Alexander DD. Long-chain omega-3 fatty acids eicosapentaenoic acid and docosahexaenoic acid and blood pressure: a meta-analysis of randomized controlled trials. Am J Hypertens. 2014; 27(7): 885-896, doi: 10.1093/ajh/hpu024, indexed in Pubmed: 24610882.

10. Hegarty B, Parker G. Fish oil as a management component for mood disorders - an evolving signal. Curr Opin Psychiatry. 2013; 26(1): 33-40, doi: 10.1097/YCO.0b013e32835ab4a7, indexed in Pubmed: 23108232.

11. Gerster H. Can adults adequately convert alpha-linolenic acid (18:3n-3) to eicosapentaenoic acid (20:5n-3) and docosahexaenoic acid (22:6n-3)? Int J Vitam Nutr Res. 1998; 68(3): 159-173, indexed in Pubmed: 9637947.

12. DeFilippis AP, Sperling LS. Understanding omega-3's. Am Heart J. 2006; 151(3): 564-570, doi: 10.1016/j. ahj.2005.03.051, indexed in Pubmed: 16504616.

13. Colomer R, Moreno-Nogueira JM, García-Luna PP, et al. $\mathrm{N}-3$ fatty acids, cancer and cachexia: a systematic review of the literature. Br J Nutr. 2007; 97(5): 823-831, doi: 10.1017/S000711450765795X, indexed in Pubmed: 17408522.

14. Dreher ML, Davenport AJ. Hass avocado composition and potential health effects. Crit Rev Food Sci Nutr. 2013; 53(7): 738-750, doi: 10.1080/10408398.2011.556759, indexed in Pubmed: 23638933.
15. Holick MF. Vitamin D deficiency. N Engl J Med. 2007; 357: 266-281.

16. Hewison M. Antibacterial effects of vitamin D. Nat Rev Endocrinol. 2011; 7(6): 337-345, doi: 10.1038/nrendo.2010.226, indexed in Pubmed: 21263449.

17. Wrzosek M, Jakubczyk A, Wrzosek M, et al. Vitamin D and the central nervous system. Pharmacol Rep. 2013; 65(2): 271-278, indexed in Pubmed: 23744412.

18. Dev R, Del Fabbro E, Schwartz GG, et al. Preliminary report: vitamin $D$ deficiency in advanced cancer patients with symptoms of fatigue or anorexia. Oncologist. 2011; 16(11): 1637-1641, doi: 10.1634/theoncologist.2011-0151, indexed in Pubmed: 21964001.

19. Bergman P, Sperneder S, Höijer J, et al. Low vitamin D levels are associated with higher opioid dose in palliative cancer patients--results from an observational study in Sweden. PLoS One. 2015; 10(5): e0128223, doi: 10.1371/journal. pone.0128223, indexed in Pubmed: 26018761.

20. Helde-Frankling $M$, Höijer J, Bergqvist J, et al. Vitamin D supplementation to palliative cancer patients shows positive effects on pain and infections-Results from a matched case-control study. PLoS One. 2017; 12(8): e0184208, doi: 10.1371/journal.pone.0184208, indexed in Pubmed: 28859173.

21. Sepehrmanesh Z, Kolahdooz F, Abedi F, et al. Vitamin D Supplementation Affects the Beck Depression Inventory, Insulin Resistance, and Biomarkers of Oxidative Stress in Patients with Major Depressive Disorder: A Randomized, Controlled Clinical Trial. J Nutr. 2016; 146(2): 243-248, doi: 10.3945/jn.115.218883, indexed in Pubmed: 26609167.

22. Holick MF. Vitamin D deficiency. N Engl J Med. 2007; 357: 266-281.

23. Englard S, Seifter $\mathrm{S}$. The biochemical functions of ascorbic acid. Annu Rev Nutr. 1986; 6: 365-406, doi: 10.1146/annurev.nu.06.070186.002053, indexed in Pubmed: 3015170.

24. Carr AC, Frei B. Toward a new recommended dietary allowance for vitamin $C$ based on antioxidant and health effects in humans. Am J Clin Nutr. 1999; 69(6): 1086-1107, doi: 10.1093/ajcn/69.6.1086, indexed in Pubmed: 10357726.

25. Doll S, Ricou B. Severe vitamin C deficiency in a critically ill adult: a case report. Eur J Clin Nutr. 2013; 67(8): 881-882, doi: 10.1038/ejcn.2013.42, indexed in Pubmed: 23549202.

26. Fukushima R, Yamazaki E. Vitamin $C$ requirement in surgical patients. Curr Opin Clin Nutr Metab Care. 2010; 13(6): 669-676, doi: 10.1097/MCO.0b013e32833e05bc, indexed in Pubmed: 20689415.

27. Marcus SL, Dutcher JP, Paietta E, et al. Severe hypovitaminosis $\mathrm{C}$ occurring as the result of adoptive immunotherapy with high-dose interleukin 2 and lymphokine-activated killer cells. Cancer Res. 1987; 47(15): 4208-4212, indexed in Pubmed: 3496958.

28. Alexandrescu DT, Dasanu CA, Kauffman CL. Acute scurvy during treatment with interleukin-2. Clin Exp Dermatol. 2009; 34(7): 811-814, doi: 10.1111/j. 1365-2230.2008.03052.x, indexed in Pubmed: 19094121.

29. Oak ASW, Jaleel T, Fening $K$, et al. A case of scurvy associated with nilotinib. J Cutan Pathol. 2016; 43(8): 725-726, doi: 10.1111/cup.12715, indexed in Pubmed: 27124705.

30. Günes-Bayir A, Kiziltan HS. Palliative Vitamin C Application in Patients with Radiotherapy-Resistant Bone Metastases: A Retrospective Study. Nutr Cancer. 2015; 67(6): 921-925, doi: 10.1080/01635581.2015.1055366, indexed in Pubmed: 26168394.

31. Yeom CH, Jung GC, Song KJ. Changes of terminal cancer patients' health-related quality of life after high dose vitamin C administration. J Korean Med Sci. 2007; 22(1): 7-11, doi: 10.3346/jkms.2007.22.1.7, indexed in Pubmed: 17297243. 
32. Vollbracht C, Schneider B, Leendert V, et al. Intravenous vitamin $C$ administration improves quality of life in breast cancer patients during chemo-/radiotherapy and aftercare: results of a retrospective, multicentre, epidemiological cohort study in Germany. In Vivo. 2011; 25(6): 983-990, indexed in Pubmed: 22021693.
33. Murata A, Morishige $F$, Yamaguchi H. Prolongation of survival times of terminal cancer patients by administration of large doses of ascorbate. Int J Vitam Nutr Res Suppl. 1982; 23: 103-113, indexed in Pubmed: 6811475.

34. Carr AC, Vissers MCM, Cook J. Parenteral vitamin C for palliative care of terminal cancer patients. N Z Med J. 2014; 127(1396): 84-86, indexed in Pubmed: 24997468. 